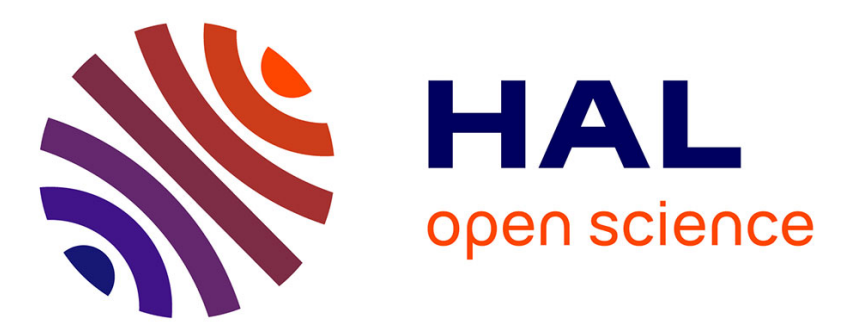

\title{
Surface and image analysis of oxides grown and spalled on heat resistant cast steels exposed to thermal cycles
}

Stéphane Baleix, Sabine Le Roux, Gérard Bernhart, Philippe Lours

\section{To cite this version:}

Stéphane Baleix, Sabine Le Roux, Gérard Bernhart, Philippe Lours. Surface and image analysis of oxides grown and spalled on heat resistant cast steels exposed to thermal cycles. Journal of Materials Processing Technology, 2001, 118 (1-3, SI), pp.321-328. 10.1016/S0924-0136(01)00860-3 . hal01703129

\section{HAL Id: hal-01703129 \\ https://hal.science/hal-01703129}

Submitted on 11 Jan 2019

HAL is a multi-disciplinary open access archive for the deposit and dissemination of scientific research documents, whether they are published or not. The documents may come from teaching and research institutions in France or abroad, or from public or private research centers.
L'archive ouverte pluridisciplinaire HAL, est destinée au dépôt et à la diffusion de documents scientifiques de niveau recherche, publiés ou non, émanant des établissements d'enseignement et de recherche français ou étrangers, des laboratoires publics ou privés. 


\title{
Surface and image analysis of oxides grown and spalled on heat resistant cast steels exposed to thermal cycles
}

\author{
S. Baleix, S. Le Roux, G. Bernhart, P. Lours* \\ CROMeP, Research Center on Tools, Materials and Processes, Ecole des Mines d'Albi-Carmaux, Campus Jarlard, 81013 Albi, France
}

\begin{abstract}
Heat resistant cast steels, used as tools for sheet superplastic forming, are oxidized in near-service thermal cycling conditions. Data from 3D roughness measurements and scanning electron microscope (SEM) micrographs are processed using image analysis software. The surface spacing parameters, the distribution and nature of the various spalled oxides as well as the surface recession of the metal substrate are investigated with respect to high temperature exposure time and related number of cycles. Based on this analysis, the nucleation, growth and spallation of oxides due to thermal stresses occurring upon cooling is discussed. It is shown that the amount of spalled oxide increases with the exposure time. Spallation results either from adhesive or cohesive rupture of the oxide. Texture of the spalled cells, strong for short exposure time, tends to vanish when the exposure time increases. Surface recession of the substrate is successfully calculated.
\end{abstract}

Keywords: Heat resistant cast steel; Cyclic oxidation; Image analysis

\section{Introduction}

Heat resistant $\mathrm{Ni}-\mathrm{Cr}-\mathrm{Fe}$ cast steels are currently used to manufacture SPF tools in which titanium sheets are blown into shape using argon pressure, i.e. superplastically formed [1]. The environmental conditions are severe as the superplastic forming (SPF) process is carried out at around $900^{\circ} \mathrm{C}$ where oxidation and spallation of oxides can alter the surface of the tools, thereby affecting the surface quality of the SPF parts produced. Choice of materials for such an application includes considerations both on the resistance to oxidation, for which high chromium content (around $25 \mathrm{wt} . \%)$ is recommended, and the mechanical strength provided by the addition of nickel- and carbide-forming minor elements [2]. In order to investigate the resistance to cyclic oxidation of such materials in real service conditions, typical SPF thermal cycles were measured in situ using thermocouples welded on at various locations on an industrial tool [3] and applied to laboratory specimens. The study of materials behaviour subject to cyclic oxidation, though widely investigated in many laboratories by thermogravimetric techniques, suffers from a lack of standardization and general recommendations that can be used by all investigators [4]. Recently, new methods to address cyclic oxidation and associated spallation of oxide scales have

\footnotetext{
* Corresponding author.

E-mail address: lours@enstimac.fr (P. Lours)
}

been proposed, such as acoustic emission [5], in addition to well-developed models to assess for oxide scale failure [6,7]. This paper is an attempt to characterize the cyclic oxidation behaviour of heat resistant cast steels using thermogravimetry and image analysis of spalled oxide layers.

\section{Oxidation kinetics}

Material tested in this study is an austenitic heat resistant cast steel, widely used in SPF tooling, referred to as GX15NiCrNb 35-26 according to the European standard prEN 31/57. Material is cyclically oxidized from $950^{\circ} \mathrm{C}$ (holding time in 1 cycle: $5 \mathrm{~h}$ ) to $750^{\circ} \mathrm{C}$ (holding time in 1 cycle: $0.2 \mathrm{~h}$ ) with a final return to room temperature [3] for periods up to $720 \mathrm{~h}$ corresponding to 120 cycles. Gravimetric data, corresponding to specimen mass increment per surface unit, are collected from two distinct kinetic measurements (Fig. 1). The first includes the total amount of material, related to oxide and substrate, involved in the oxidation process leading to the determination of the oxidation kinetics. Only diffusion mechanisms are taken into account to derive this power law. The weighting includes the mass of oxide that spalled during cycling as specimen mass is measured following final return to room temperature within covered crucibles. The second is the residual mass of specimen after oxidation and spallation upon cooling. This measurement gives access to the spallation kinetics in which 


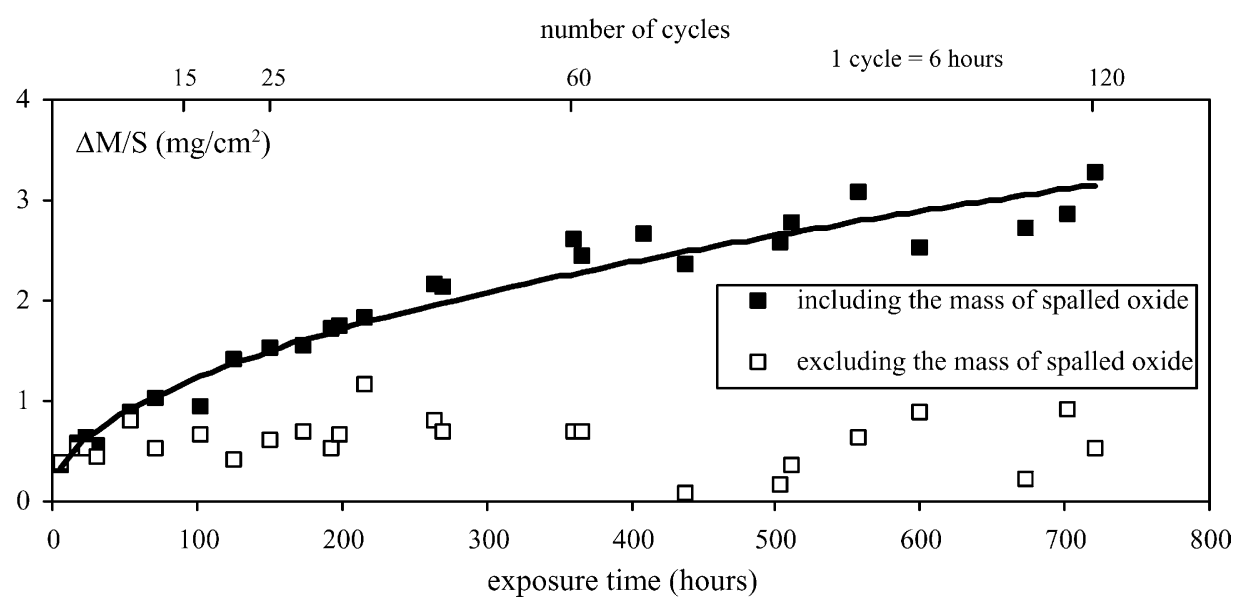

Fig. 1. Oxidation and spallation kinetics of austenitic heat resistant cast steel (see text for details).

the effect of differential thermal stresses and bond strength at the interface metal/oxide are included.

Up to a threshold exposure time of around $54 \mathrm{~h}$ corresponding to nine cumulative cycles, both plots are similar indicating that no significant spallation occurs. Below this exposure, the attack of the alloy is essentially protective and both kinetics are close to parabolic. Above this exposure, the two plots diverge as the amount of spalled oxide gradually increases. Spallation can be related to the relief of oxide growth stress and most likely of stress due to differential thermal expansion coefficients between the substrate and the oxide. Those thermal cycling stresses lead to moderate or extensive spallation that will be investigated with complementary 3D roughness measurements, scanning electron microscope (SEM) observations and image analysis.

\section{Scanning electron microscope investigation}

Backscattered electron SEM images, coupled with energy dispersive spectroscopy (EDS) of the surface of cycled

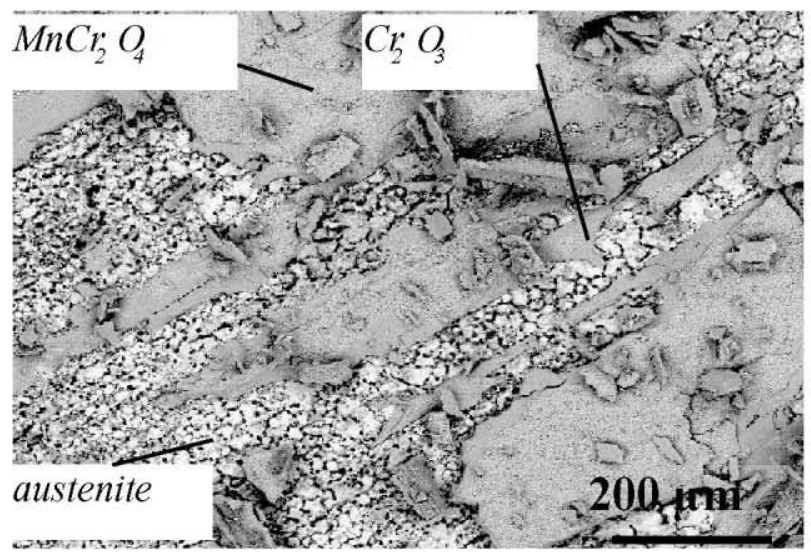

(a) specimens, allows the determination of the various phases involved in the oxidation and spallation processes. In order to investigate zones large enough to be satisfactorily representative with a good resolution, acquisition of $3 \mathrm{~mm} \times$ $2.8 \mathrm{~mm}$ images, corresponding to 30 joined fields subsequently assembled, is performed. The size of the digitalized image is $3435 \times 2868$ pixels. The analysis of the various contrasts, the EDS spectra and additional X-ray diffraction data showed that three phases are predominant, namely the austenite substrate, the chromium oxide $\mathrm{Cr}_{2} \mathrm{O}_{3}$ and the spinel $\mathrm{MnCr}_{2} \mathrm{O}_{4}$. Finer investigation shows additional $\mathrm{SiO}_{2}$ at the interface metal/oxide that acts as a healing layer and generally improves oxidation resistance [8]. Fig. 2a is a low magnification elementary SEM image of a specimen cyclically oxidized during $150 \mathrm{~h}$, then cooled to room temperature. Clearly shown on the micrograph are the three different phases described above. Fig. $2 b$ shows the details of a zone that suffered spallation. On the left-hand side of the micrograph, the oxide scale has fractured and detached revealing the underlying austenite substrate. On the righthand side, note the presence of a crack along the remaining

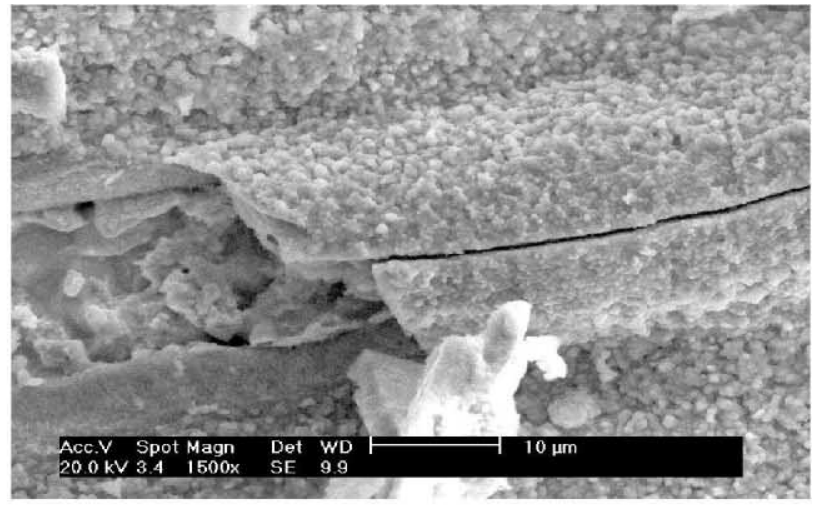

(b)

Fig. 2. (a) Low magnification micrograph showing the different phases at the surface of a specimen cyclically oxidized for $150 \mathrm{~h}$, (b) surface morphology showing spallation by buckling. 
oxide scale that shows a markedly bowed shape. This would suggest that detachment of the oxide tends to proceed through local decohesions and buckling of the scale due to compressive straining on cooling. In this case, spallation results from the occurrence of through-thickness cracks in the buckled oxide subject to tensile stress. A thorough inspection of additional SEM images show, in some cases, that spallation can result either from adhesive rupture along both the austenite substrate and the $\mathrm{Cr}_{2} \mathrm{O}_{3}$ scale and $\mathrm{Cr}_{2} \mathrm{O}_{3}$ and the spinel $\mathrm{MnCr}_{2} \mathrm{O}_{4}$ or cohesive within the $\mathrm{Cr}_{2} \mathrm{O}_{3}$ scale.

\section{Three-dimensional roughness measurements}

Stylus roughness measurement captures height data in two dimensions only. For most engineering surfaces, this holds true and a single trace is used as a basis for roughness analysis. Oxidized and spalled surfaces are cases where the surfaces have no clearly defined lay and an average of say 100 profile measurements, yields more accurate results. Those 100 profiles correspond to an investigated area of $24 \mathrm{~mm}^{2}$. A mathematical interpolation treatment is used to visualize the top view topography with various grey levels corresponding to various heights: black is low and white is high (Fig. 3). The lateral and horizontal resolutions are $6 \mu \mathrm{m}$ while the height resolution varies from 0.16 to $0.3 \mu \mathrm{m}$ depending on the total height range of the image.

In addition to standard parameters such as $R_{\mathrm{a}}$ or $R_{\mathrm{t}}$, it is worth focussing on what are called the spacing or hybrid (spacing and depth) parameters. $P_{\mathrm{c}}$ is the peak count on the profiles related to material that crosses alternatively two predefined cutting depths at $\pm 2 \mu \mathrm{m}$ from the profile mean line. The evolution of $P_{\mathrm{c}}$ versus the exposure time is given in Fig. 4. After a rapid increase during the first $50 \mathrm{~h}, P_{\mathrm{c}}$ reaches a peak and then drops abruptly to level off starting at around $120 \mathrm{~h}$. The first part of the plot corresponds to the growth of a fine layer of oxide unlikely to spall. Peak exposure time roughly corresponds to the threshold point of divergence of the plots in Fig. 1. Consistently, up to this exposure, the roughness $R_{\mathrm{a}}$ and $R_{\mathrm{t}}$ continuously increases (Fig. 5). Further

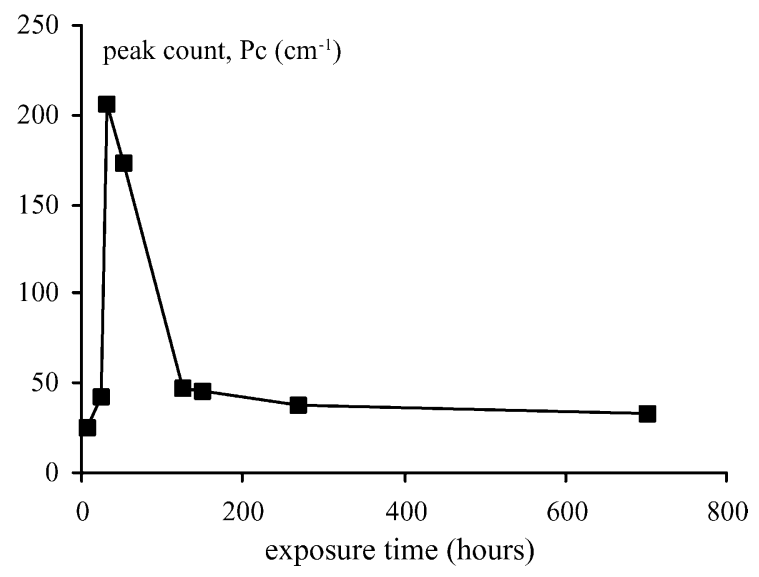

Fig. 4. Peak count $P_{\mathrm{c}}$ versus exposure time.

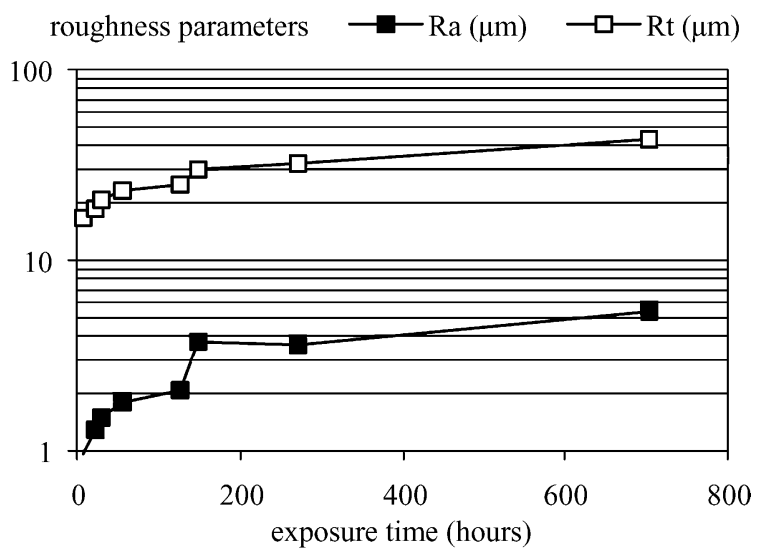

Fig. 5. Roughness parameters $R_{\mathrm{a}}$ and $R_{\mathrm{t}}$ versus exposure time.

decrease of $P_{\mathrm{c}}$ indicates the heavy spallation of oxides where spalled cells gradually enlarge. Saturation is reached when the proportion of spalled areas is large enough to promote only little variation of $P_{\mathrm{c}}$. On the flat part of the curve, $P_{\mathrm{c}}$ is related to the roughness of the damaged substrate following successive oxide growth and spall.
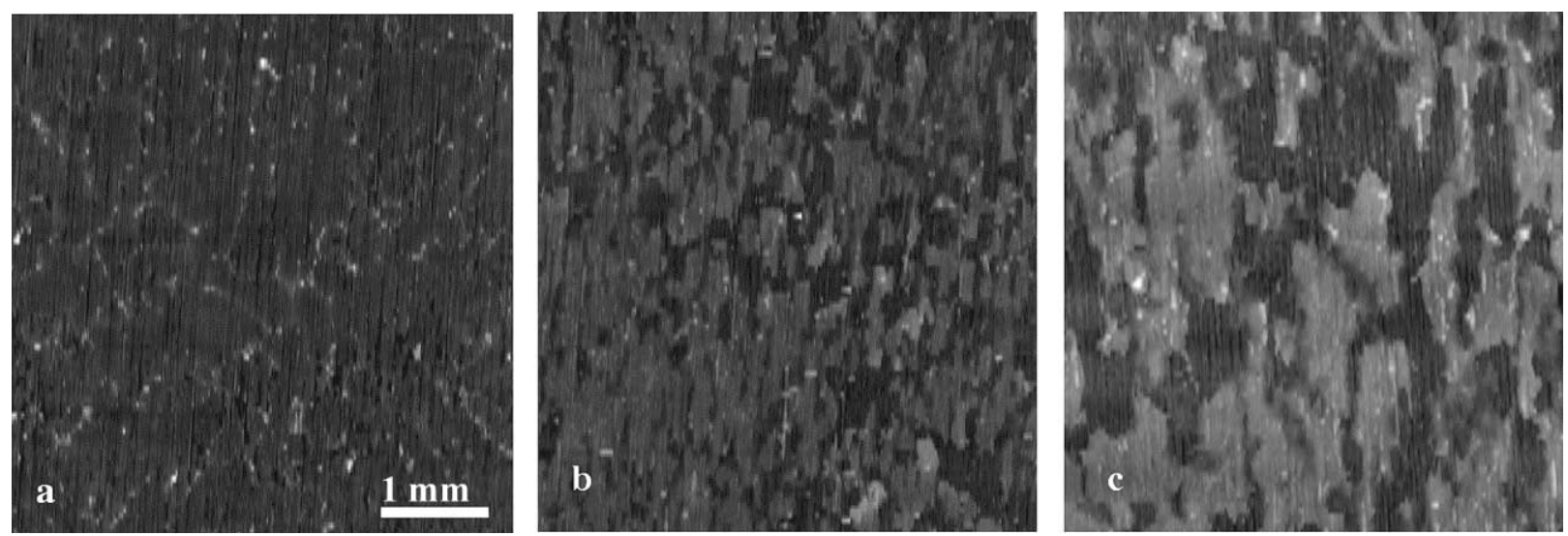

Fig. 3. Top view images after interpolation treatment of 3D roughness topographies for various cyclic oxidation exposure times: (a) 24; (b) 150; (c) 558 h. 


\section{Image analysis}

Image analysis is used to derive quantitative data from SEM and 3D roughness grey level images. As indicated previously, the two techniques are complementary. SEM analysis allows the recognition of the various phases that show at the surface of the material after completion of a given number of oxidation cycles. In addition, the shape, size and surface fraction of those phases can be derived. Roughness investigation gives the height distribution of those phases. The coupled treatment of both data allows the surface recession due to metal loss to be calculated.

\subsection{Scanning electron microscope images}

From the chemical contrast typical of backscattered electron images, two distinct thresholds are defined within the whole range of grey levels constituting the micrographs. The first and second thresholds correspond to the upper limit of occurrence of, respectively, the austenite substrate and the chromium oxide. The spinel is located above the second threshold. The global methodology to segment the images is described in Table 1 [9]. An example of the result of such image processing is given in Fig. 6 showing the surface of specimens after various exposure times. Areas with black contrast, corresponding to the austenite, indicate zones where the oxide fully spalled adhesively from the substrate. In deep grey areas, corresponding to the location of $\mathrm{Cr}_{2} \mathrm{O}_{3}$, spallation results either from adhesive or cohesive fracture. Light grey areas, corresponding to the spinel, represent the surface fraction where no spallation occurred.

\subsection{Three-dimensional roughness images}

Similarly, as for SEM images, thresholds are defined to distinguish phases on the top view $3 \mathrm{D}$ roughness images. In this case, however, grey levels are no longer related to the chemical composition but are associated with the height distribution of each phase. The threshold segmentation of 3D roughness images ( $T_{i}^{\prime}$ for a given phase $i$ ) results from the previous SEM analysis giving the threshold $\left(T_{i}\right)$ and the surface fraction $\left(f_{i}\right)$ of each phase. The methodology describing the different steps for the analysis is set out in Table 2: the surface fraction $f_{i}^{\prime}$ of a phase $i$ on the 3D roughness image is taken equal to the surface fraction of the same phase on the SEM image $\left(f_{i}\right)$. This allows us to set the threshold $T_{i}^{\prime}$ corresponding to this phase on the 3D roughness image. The analysis of such segmented roughness images leads to the determination of phase height, which is the total roughness of the substrate and the thickness of the oxide.

Table 1

Methodology for the SEM image analysis procedure

\begin{tabular}{|c|c|c|c|c|}
\hline \multirow[t]{2}{*}{$\begin{array}{l}\text { SEM images } \\
(712 \times 484 \\
\text { pixels })\end{array}$} & $\begin{array}{c}\text { Digitalized } \\
\text { assembled image } \\
(3435 \times 2868 \\
\text { pixels })\end{array}$ & $\begin{array}{c}\text { Contrast } \\
\text { optimization: } \\
\text { median filtering, } \\
\text { exponential } \\
\text { anamorphosis }\end{array}$ & $\begin{array}{l}\text { Phase detection: } \\
\text { entropy } \\
\text { maximization } \\
\text { based } \\
\text { thresholding }\end{array}$ & $\begin{array}{c}\% \text { austenite } \\
\% \mathrm{Cr}_{2} \mathrm{O}_{3} \\
\% \mathrm{MnCr}_{2} \mathrm{O}_{4}\end{array}$ \\
\hline & $\begin{array}{c}\text { Cell size } \\
\text { Cell shape } \\
\text { Cell orientation }\end{array}$ & $\begin{array}{c}\text { Individual } \\
\text { analysis: labelling } \\
\text { and parameters } \\
\text { extraction }\end{array}$ & $\begin{array}{l}\text { Morphological } \\
\text { filtering: hole } \\
\text { filling, edge-off } \\
\text { operation }\end{array}$ & \\
\hline
\end{tabular}

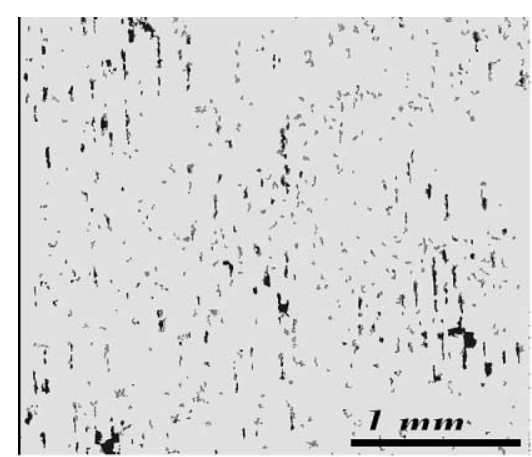

(a)

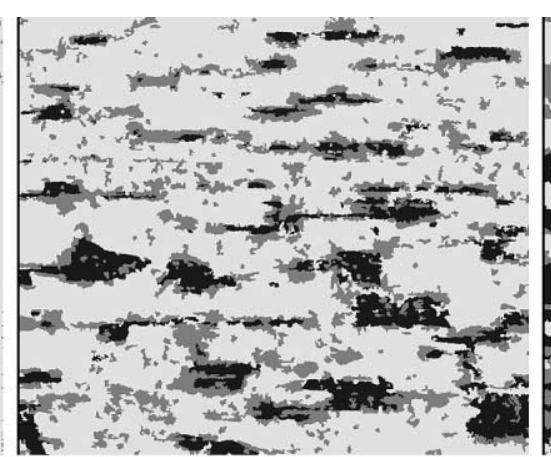

(b)

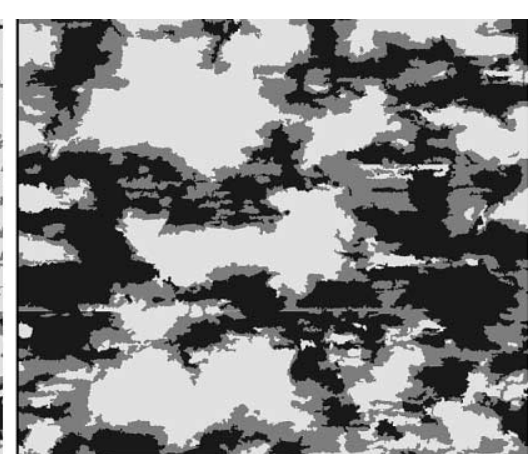

(c)

Fig. 6. Discrimination of phases on oxidized surfaces for various exposure times (a) 24, (b) 270 and (c) $720 \mathrm{~h}$, from image analysis of SEM micrographs. 
Table 2

Methodology of the image analysis from phase identification to phase height distribution

\begin{tabular}{|c|c|c|c|c|c|c|}
\hline & phase i & & ong $g$ & & surface frac & \\
\hline SEM analysis & BSE contrast & $\Rightarrow$ & Ti & & $f i$ & П \\
\hline Roughness analysis & height & 幽 & $T^{\prime} i$ & 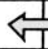 & $f^{\prime} i=f i$ & $\checkmark s$ \\
\hline
\end{tabular}

\section{Discussion}

\subsection{Surface fraction of phases}

The surface fraction of a phase $i, A_{\mathrm{A}}(i)$ is calculated as the ratio of the number of pixels corresponding to this phase $\left(A_{i}\right)$ to the total number of pixels of the SEM image $\left(A_{\mathrm{t}}\right)$. Ratios corresponding to the austenite phase, $A_{\mathrm{A}}$ (austenite), and to $\mathrm{Cr}_{2} \mathrm{O}_{3}, A_{\mathrm{A}}\left(\mathrm{Cr}_{2} \mathrm{O}_{3}\right)$, quantify, respectively, the proportion of spallation at the substrate-oxide interface and within the oxide scale (or at the $\mathrm{Cr}_{2} \mathrm{O}_{3} / \mathrm{MnCr}_{2} \mathrm{O}_{4}$ interface). The complementary ratio $A_{\mathrm{A}}\left(\mathrm{MnCr}_{2} \mathrm{O}_{4}\right)$ relates to the $\mathrm{MnCr}_{2} \mathrm{O}_{4}$ phase that lies at the very top surface of specimens where no spallation occurred. Fig. 7 shows that the proportion of spalled cells increases steadily with the exposure time. In addition, the surface fraction of spall is estimated from the oxidation kinetics data by calculating the adherence factor $\operatorname{Ad}(\%)$ defined as the ratio of the mass of oxide remaining at the surface of the specimen after thermal cycles to the mass of total oxide grown at the surface of the specimens [10].

For comparison, the values of 100-Ad(\%), indicating the tendency to spallation, are plotted in Fig. 7. Note the good correlation between the evolution of $100-\mathrm{Ad}(\%)$ and $A_{\mathrm{A}}$ (austenite $+\mathrm{Cr}_{2} \mathrm{O}_{3}$ ). Indeed, the adherence factor refers to the proportion of oxide that spalls during thermal cycling but does not give insight to the nature of oxide that does spall. In addition, contrary to the image analysis approach, no information on the location of the fracture that induces spallation can be derived from the calculation of the adherence factor.

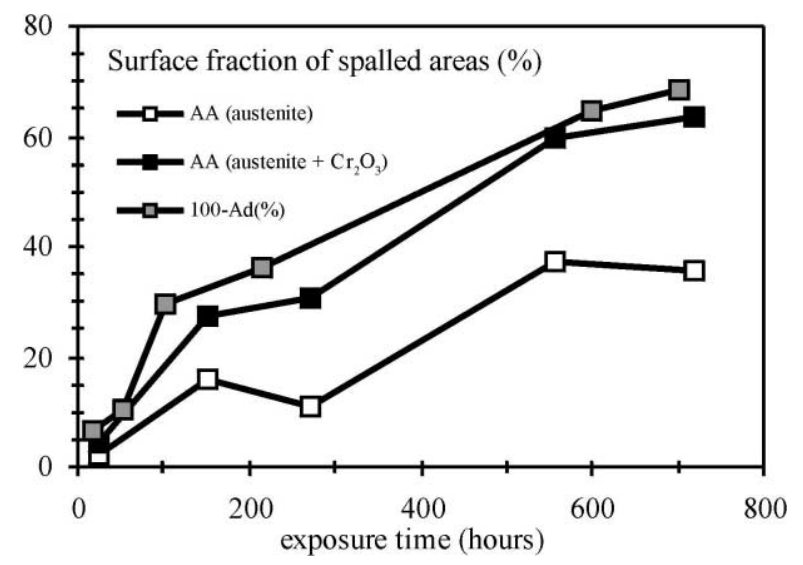

Fig. 7. Surface fraction of spalled areas versus exposure time.

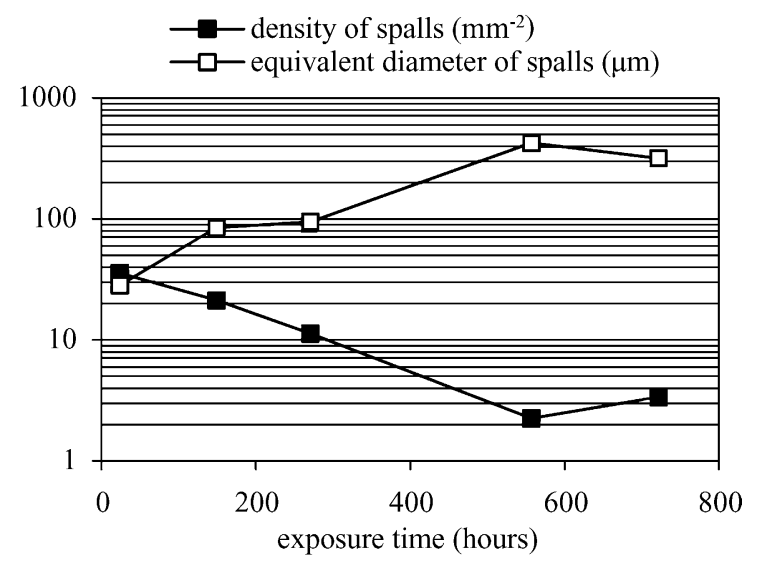

Fig. 8. Density and equivalent diameter of spalls versus exposure time.

\subsection{Morphology of spalled cells}

In addition to the surface fraction, the size, shape and texture of each of the detected spall can be determined from the analysis of SEM images. Fig. 8 gives the surface density and the average equivalent diameter of spalls. Density corresponds to the number of spalled cells per surface unit and equivalent diameter is defined as $2 \sqrt{S / \pi}$, where $S$ is the area of spalls. Plotted in the figure are only those parameters characteristic of spalls resulting from adhesive rupture at the substrate/oxide interface. At the early stage of oxidation, the high value of spall density is due to the occurrence of a large number of spallation nucleation sites. Correlatively, the average diameter of the spalls is low. Over longer exposure times, the surface density of spalls decreases and the average size of spalls increases as spalled cells tend to coalesce.

Fig. 9 shows the evolution of the shape factors of the spalls: compacity and aspect ratio. Compacity, corresponding to the reciprocal of circularity, is defined as $P^{2} / 4 \pi S$, where $P$ and $S$ are the perimeter and the area of spalls, respectively. The lowest value of compacity, 1 , indicates a perfect circular shape. Higher values represent non-circular shapes. Increase in compacity indicates either a pure distortion of the shape of the spalls resulting in, for a constant perimeter, a decrease of the surface; or a facetting of the perimeter line of the spalls resulting in, at constant surface, an increase of the perimeter length. The aspect ratio, or Feret ratio, is defined as the ratio of the length to the breadth of the rectangles that circumscribe the spalls. Values close to 1 indicate spalls with roughly circular or 


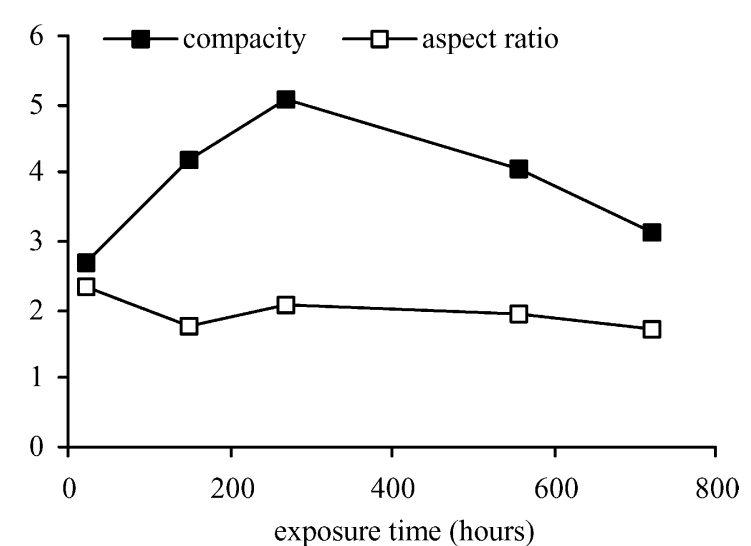

Fig. 9. Average compacity and aspect ratio of spalls versus exposure time.

square shapes while higher values characterize elongated spalls. The overall decrease of the aspect ratio suggests that, for short exposure, spallation is more anisotropic than for long exposure (Fig. 9).

This is confirmed by the analysis of the orientation of the spalls. The orientation of spalls is defined here as the angle between the direction of maximum Feret length and the direction of the traces of machining on the surface of specimens. The cumulative length corresponding to a given orientation divided by the cumulative length for all orientations, plotted versus the angle in the range $0-180^{\circ}$, is used to address the textural effect of spallation (Fig. 10). For $24 \mathrm{~h}$ of exposure, the spall elongation along the $0^{\circ}$ orientation, around $40 \%$ in length, is very high. As the exposure time increases, texture tends to be less significant. However, though more dispersion is observed in the plot, texture does not vanish completely. In the angular range $0-5^{\circ}$, the length percent varies from 60 to $20 \%$ between 24 and $720 \mathrm{~h}$ exposure. This indicates that spallation tends to develop preferentially along the peaks or valleys of the grinding traces, which is particularly significant for short exposure time when spalled cells have not yet coalesced. These results suggest that not only the roughness but also the texture of the surface prior to oxidising have major influences on the resistance of the material to oxidation and spallation.

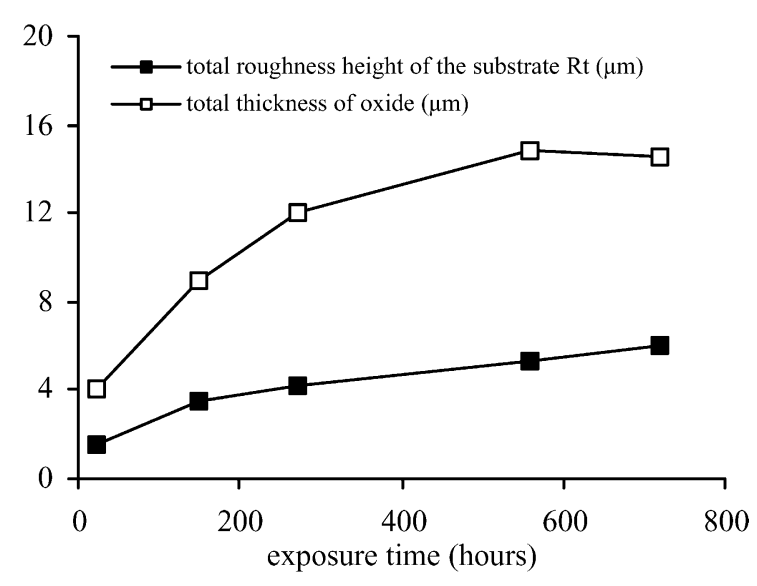

Fig. 11. Total roughness of substrate and total thickness of oxide versus exposure time.

\subsection{Oxide thickness and surface recession of the substrate}

From 3D roughness images, one can determine the total roughness of the substrate and the total thickness of the oxide including $\mathrm{Cr}_{2} \mathrm{O}_{3}$ and $\mathrm{MnCr}_{2} \mathrm{O}_{4}$ (Fig. 11). The oxide thickness increases as the exposure time increases according to a power law similar to that characteristic of the oxidation kinetics shown in Fig. 1.

Depending on the strength of the substrate/oxide interface, two possible routes of spalling have been proposed. If the oxide/metal interface is more resistant to rupture than the oxide itself, spallation occurs following initial compressive shear cracks in a mode known as wedging. If interfacial adhesion is poor, due for instance to void segregation at the interface, compressive straining provokes buckling of the oxide (Fig. 2b). In this case, the critical temperature drop $\Delta T_{\mathrm{c}}$ to promote unstable buckling resulting in the decohesion of the scale, is expressed by [11]

$\Delta T_{\mathrm{c}}=\frac{1}{\Delta \alpha}\left(\frac{1.052 \xi^{4}}{R^{4}}+\frac{1.041 \gamma_{\mathrm{F}}}{E_{\mathrm{o}} \xi}\right)^{1 / 2}$

where $\Delta \alpha$ is the difference of thermal expansion coefficient between the oxide and the substrate, $\xi$ the thickness of the oxide, $E_{\mathrm{o}}$ the Young's modulus of the oxide, $R$ the radius of

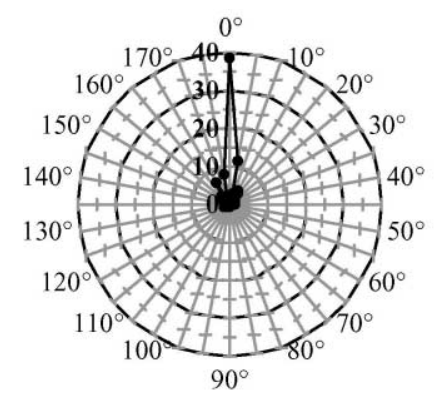

(a)

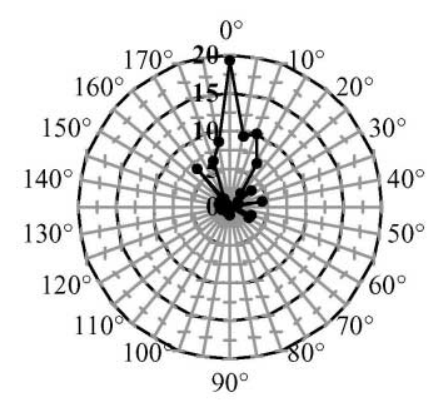

(b)

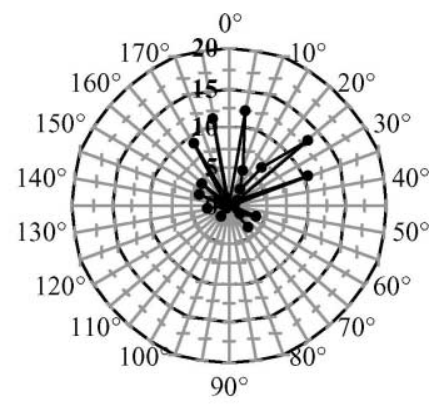

(c)

Fig. 10. Length percent of spalls versus orientation for different exposure times: (a) 24; (b) 150; (c) $720 \mathrm{~h}$. 


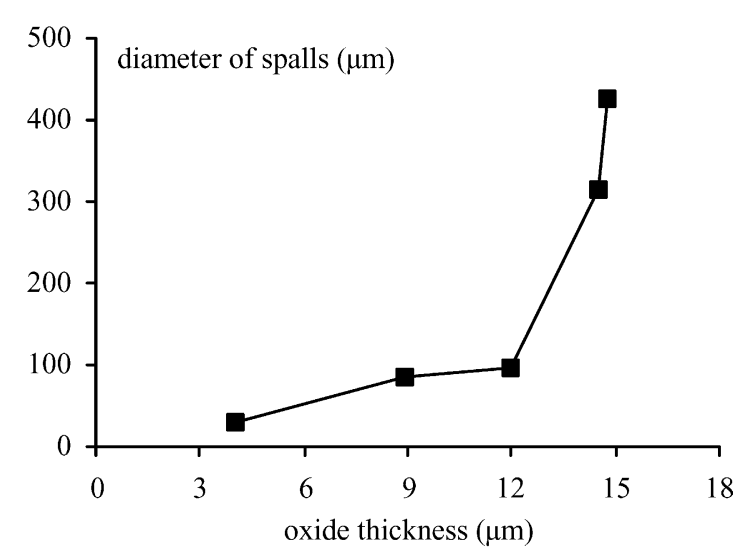

Fig. 12. Equivalent diameter of spalls versus oxide thickness.

the area that initially suffered decohesion and $\gamma_{\mathrm{F}}$ the fracture energy at the metal/oxide interface.

One major problem for modelling spallation is the determination of the fracture energy $\gamma_{\mathrm{F}}$. This energy may be directly measured from indentation tests at the metal/oxide interface, but up to now, no reliable values are available. $\Delta T_{\mathrm{c}}$ can be estimated by measuring the acoustic activity or the weight loss of a specimen during cooling following long term exposure to high temperatures. From the determination of $\Delta T_{\mathrm{c}}$ and making an assumption on the value of $R$, it is indeed possible to determine $\gamma_{\mathrm{F}}$. Image analysis can be rewarding for determining a precise relationship between the spall diameter and the oxide thickness (Fig. 12) that can in turn be related to the exposure time (Fig. 11). Associated with values of $\Delta T_{\mathrm{c}}$, this can be used to determine $\gamma_{\mathrm{F}}$.

As exposure time increases and due to metal loss during oxidation, the metal/oxide interface tends to move inwards relative to its initial position resulting in some surface recession. In addition, the substrate becomes deeply crevassed leading to the establishment of a rough surface as shown in Fig. 13. Assuming a homogeneous $\mathrm{Cr}_{2} \mathrm{O}_{3}$ oxide layer, the surface recession $r$ can be estimated using the

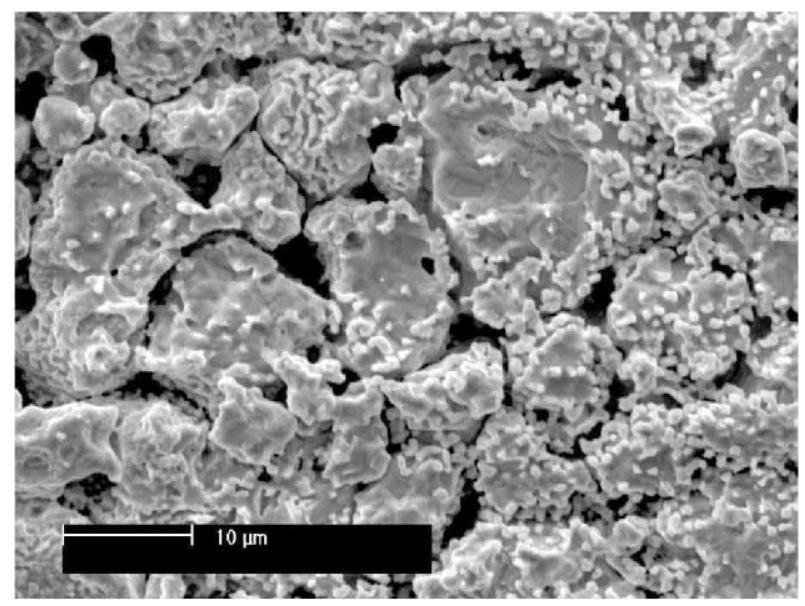

Fig. 13. Morphology of the substrate surface after oxide chemical descaling.

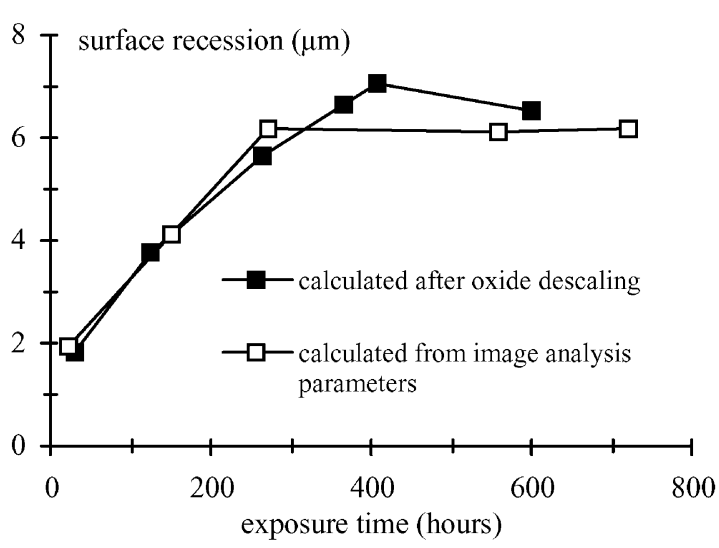

Fig. 14. Substrate recession of the substrate versus exposure time.

following relationship [12]:

$r=\frac{\rho_{\mathrm{o}} \xi S_{\mathrm{o}}-S_{\mathrm{t}}(\Delta m / S)}{\rho_{\mathrm{m}} S_{\mathrm{t}}}$

where $\rho_{\mathrm{o}}$ and $\rho_{\mathrm{m}}$ are the densities of the oxide and the substrate, respectively, $S_{\mathrm{o}}$ the surface covered by the oxide, $S_{\mathrm{t}}$ the total surface investigated, $\xi$ the oxide thickness and $\Delta m / S$ is the experimental specimen weight variation per surface unit used to plot the spallation kinetics in Fig. 1. Fig. 14 shows the variation of the surface recession versus the exposure time calculated with the above formula using parameters determined by image analysis and experimental thermogravimetry. Until about $700 \mathrm{~h}$ of exposure, surface recession increases with exposure time and tends to saturate beyond around $300 \mathrm{~h}$ exposure. Note that the surface recession is expected to increase dramatically for extended exposure time following unavoidable break away oxidation. For comparison and validation of the image analysis approach, surface recession was measured using weight loss of the metal after chemical descaling of the oxides that had grown on the specimens. The evolution of the experimental surface recession is plotted on the same graph of Fig. 14 and shows a good correlation with the calculated values.

\section{Conclusion}

Image analysis of combined SEM photographs and 3D roughness topographies is used to investigate spallation of oxides on heat resistant cast steels exposed to thermal cycles. Quantitative data on the surface fraction of oxide that spalled after cooling from the oxidation temperature, as well as on the size, shape, and texture of spalled cells are derived.

Evolution of the surface fraction of spalled oxides versus exposure time and related number of thermal cycles showed that the degradation of materials is enhanced as exposure time is extended. Initial surface texture due to machining of the metal substrate induces preferential fracture and detachment of oxide, particularly for short exposure times.

The analysis allows the determination of a relationship between the exposure-time-dependent size of spalls and the 
oxide thickness. This can be used, provided the critical temperature drop for spallation is known, to estimate the fracture energy at the metal/oxide interface that, in turn, is used to model spallation. Finally, surface recession due to metal loss during oxidation has been satisfactorily calculated.

The method presented in this paper proved to be relevant for addressing the mechanisms of oxide growth and oxide scale failure on heat resistant cast steels and can be rewarding for studying other types of materials exposed to high temperature cyclic oxidation.

\section{Acknowledgements}

The authors gratefully acknowledge Dr. Paul Gaborit for his responsiveness and fruitful collaboration in data processing as well as ACB/GEC Alsthom, Aubert \& Duval, CEAT/ CTMS, Dassault Aviation, Hurel Dubois, Manoir Industries, Prodem and SNECMA for their financial support.

\section{References}

[1] C.H. Hamilton, A.K. Ghosh, ASM Handbook, Vol. 14, ASM, 1988, pp. 853-873.

[2] M. Blair, ASM Handbook, Vol. 1, ASM, 1990, pp. 908-929.

[3] S. Baleix, et al., in: J.J. Skrzypek, R.B. Hetnarsky (Eds.), Proceedings of the Third International Congress on Thermal Stresses, Cracow, 1999, pp. 317-320.

[4] J.R. Nicholls, M.J. Bennett, in: Proceedings of the EFC Workshop, Event No. 228, Frankfürt, 1999.

[5] S. Rajendran Pillai, et al., Oxid. Met. 49 (5-6) (1998) 509-530.

[6] H.E. Evans, Int. Mater. Rev. 40 (1) (1995) 1-40.

[7] P. Hancock, J.R. Nicholls, Mater. High Temp. 12 (2-3) (1994) 209218.

[8] F.H. Stott, Mater. Sci. Technol. 5 (1989) 734-740.

[9] M. Coster, J.L. Chermant, Précis d'Analyse d'Images, Les Presses du, CNRS 2nd Edition, Paris, 1989.

[10] G.R. Rundell, Met. Progr. (1985) 51-58.

[11] A.G. Wells, et al., in: J.V. Cathcart (Ed.), Stress Effects and the Oxidation of Metals, AIME, 1975, pp. 220-224.

[12] S. Baleix, Thèse de Doctorat de l'Université Paul Sabatier, Toulouse, France, 1999. 